2019 Global Fashion Management Conference at Paris Proceedings: 804-809 (July 2019) https://doi.org/10.15444/GFMC2019.08.02

\title{
THE INFLUENCE OF CROSS-CULTURAL EFFECT ON KÉRASTASE (L'OREAL GROUP) CONSUMER-BRAND RELATIONSHIP AND ENGAGEMENT
}

\author{
Pedro Nobre, L'Oreal, Portugal \\ Ricardo Godinho Bilro, Instituto Universitário de Lisboa (ISCTE-IUL), Business \\ Research Unit (BRU-IUL), Portugal ${ }^{1}$ \\ Sandra Maria Correia Loureiro, Instituto Universitário de Lisboa (ISCTE-IUL), \\ Business Research Unit (BRU-IUL), Portugal
}

\begin{abstract}
Introduction

Since their appearance, social media platforms (SMP) have attracted large amounts of users, many of whom have merged these networks into their daily life (Boyd \& Ellison, 2007), which in consequence attract the interest of companies due to the potential to broadcast their marketing messages to their audiences (Cvijikj \& Michahelles, 2013). In fact, SMP's have changed the way consumers relate with brands, as they are no longer passive receivers of brand messages (Men \& Tsai, 2014). Today, consumers use technology to start conversations with brands, build connections, and are also able to generate digital content within online communities. For marketers, this new digital era reveals to be a challenge as they seek to leverage social media with relationship purposes, particularly keeping consumers engaged (Sklar, 2013). Additionally, global brands face an upper challenge as consumers' cross-cultural context is highly determinant of their engagement.
\end{abstract}

Having the above-mentioned scenario as starting point, how does this apply to luxury brands? This specific type of brands commonly has a "think global, act local" mindset. Nowadays, with the need of a social media marketing strategy that increase consumerbrand relationship and engagement, brands and marketers must understand not only the new and empowered consumer motivations but also what drive's their engagement in a cross-cultural environment.

Consequently, the aim of this research is to understand the influence of cross-cultural effect on consumer-brand relationship and engagement through social media platforms. Based on this, we purpose to answer to the following research questions: (i) is the level of engagement obtained by the content created by Kérastase on social media platforms affected differently according to culture? (ii) are there any differences between consumers of different cultures and their relationship to the different topics covered by luxury brands on their social media platforms?

\section{Theoretical background}

During the late 1970's and early 1980's a growing interest in business relationships emerged. Some authors (Mulki \& Stock, 2003) believe this was a result of firm's development in more advanced economical countries, which lead them to grow globally, connecting with their consumers through information technologies, while being service

\footnotetext{
${ }^{1}$ bilro.ricardo@gmail.com
} 
and info-oriented. Hunt \& Morgan (1994) point the rise of strategic network competition with companies competing within their value chain as responsible to the rise of this trend. In fact, Leonard Berry (1983) brought up for the first time the term "Relationship Marketing" (RM) to the services marketing literature, defining it as attracting, maintaining, and enhancing customer relationships. Since then, several authors presented distinct points of view on this subject. For some authors, RM was a logical development of the marketing management tradition, involving only a minor shift in thinking from transactions to relationships (Berry, 1983; Parvatiyar \& Sheth, 2000; Sheth \& Parvatiyar, 1995). For others, however, relational perspectives offered a more radical shift in marketing thinking (e.g., Grönroos, 1994; Gummesson, 1996).

In turn, engagement undergoes enormous popularity among practitioners. This construct has been reviewed in a variety of different academic contexts, such as sociology, psychology, educational psychology and organizational behavior (Hollebeek, 2011b). However, it was only during the last few years that we face the growing interest of the topic within the marketing literature, which underline brand engagement as a way to create great value to companies (Brodie et al., 2011; Brodie et al., 2013). While a growing line of research continues to contribute to the development of the consumer engagement construct, several research streams have point out engagement as an interactive relationship between a subject and a particular object, thus reflecting a motivational state of the subject (Hollebeek, 2011a). It is further understood as a dynamic, iterative and value co-creating process, as well as predictive of consumer loyalty outcomes (Bowden, 2009; Brodie et al., 2011). The brand is usually seen as the object (Sprott, Czellar, \& Spangenberg, 2009; van Doorn et al., 2010) and the consumer as the subject of the relationship (Bowden, 2009). Vivek, Beatty, \& Morgan (2012) argue that engagement even enhances the understanding of consumer brand relationships and is a relevant component of relationship marketing.

Concerning the cross-cultural effects, previous research highlight that consumers differ in their service quality expectation based on their culture (Doonthu \& Yoo, 1998). In general, consumer cultural values affect their expectations and perceptions of products and services (Kueh \& Voon, 2007). Thus, given the fact culture may impact the way people behave and interact, it is imperative to examine cultural influence. Culture has been shown to affect marketing, including advertising, marketing strategies and buying habits (e.g., Grier \& Brumbaugh, 1999; Simester et al., 2000), but relatively little theoretical and empirical work is available in a cross-cultural adaptation of emerging technology of social media platforms.

Clustering countries and/or cultures based on their similarities or differences was carried out by different authors (e.g. Hofstede, Trompenaars). The clustering can be based on cultural dimensions, which have been developed by several authors and which aims to describe different cultures. One of the most well-known empirical study involving cultural dimensions was carried out by Geert Hofstede in 1960s and 70s when he was involved in a survey conducted among IBM employees. Hofstede's study was in the beginning based on the data from 40 different countries, later it expanded to 50 countries. Hofstede's research first identifies four cultural dimensions (Power distance, Individualism, Masculinity and Uncertainty Avoidance) and later a fifth dimension (Long-Term Orientation) was added (Hofstede, 1978). 


\section{Methodology}

To pursue our study, we decide to develop a netnography methodology (Kozinets, 2002), which may be described as an online marketing research technique that provide consumer insights. To undertake this research, we choose to focus on Kérastase, a luxury haircare brand from L'Oreal Group. In order we could compare and analyze the cultural differences, we decide to consider four different countries in distinct continents: United Sates of America (USA), United Kingdom (UK), India (IND) and South Africa (SA). Although they are geographically distant, they have in common the same language (English). Concerning the social media platforms to consider, we had in mind that the most representative worldwide online brand communities are Facebook and Instagram. However, we only consider Facebook as the Instagram account for Kérastase it's a global account and do not allow a comparative cultural study. In this sense, we collect the content through the Facebook accounts of Kérastase at USA, UK, IND and SA, with a time-range sample of contents from January 2016 to August 2018. A resume of the total amount of comments interactions can be seen on Table 1 .

Once we collect the sample content, the next stage of this netnography process was to develop a sentiment analysis to understand the consumers' interactions towards this brand. To carry on with a sentiment analysis, we decide to use a text-mining technique, which is capable of examining a vast amount of data precisely (Fan et al., 2006).

\section{Preliminary findings}

With this research authors aim to understand the cross-cultural effect on consumerbrand relationship and engagement through social media platforms in four Englishspeaking countries from four different continents. To do so, we select the luxury brand Kérastase. This brand is a French-based international luxury haircare brand that is part of the portfolio of the multinational company L'Oréal Group. We choose Facebook as the Kérastase social media platform to be analyzed. In this SMP this brand has a strong global presence with 3 Million members, as a sum of 72 countries accounts. The Netnography was performed during August and September 2018 and it considered the analysis of consumers' comments on both from January 2016 to August 2018.

In terms of general analysis, and despite the discrepancy between active user numbers per community, the user engagement in the online communities is similar. Moreover, Kérastase provides a specific content plan shared among all countries to promote a certain level of standardization, so we could expect the possibility of finding these contents equally engaging. Concerning the global sentiment analysis, Kérastase consumers from all countries showed to agree $(\sim 93 \%)$ with the content the brand publish online and put little irony in their comments $(\sim 99 \%)$. Nevertheless, consumers in USA and UK had a more subjective emotional tone in their interactions, while IND and SA consumer interactions were mostly objective. Still regarding the subjectivity versus objectivity analysis, we may find that the subjectivity from USA and UK consumers seems to be correlated with positive interactions $(\sim 86 \%)$, while the objectivity for IND and SA seems to be strongly attached to the lack of opinion or neutrality of the comments $(\sim 64 \%)$. These findings might suggest that USA and UK consumers perceive the content as more interesting. We are also able to highlight that all consumer's interact with positive sentiments associated to their comments, i.e, the average polarity associated to the interactions of each community is positive (above 3.5). This is an excellent result for Kérastase brand as it is aligned with the company goal of $100 \%$ brand love from consumers, which may be achieved through high levels 
of positive engagement and supported through an always-on structured content strategic plan.

Regarding the topic sentiment analysis, the polarities of the identified topics for the four countries in analysis are neutral (USA: 3.44; UK: 3.31; IND: 3.28; SA: 3.41), although the interactions from USA and UK have slightly higher polarity averages. Taking a closer look to the frequency of each polarity scale, it is possible to stress out that USA and UK present more positive interactions, which might suggest that the content produced by Kérastase brand may be more relatable to western cultures as it has Frenchorigins.

In conclusion, we can underline that Kérastase consumers in all four countries in analysis spend most of their time sharing the brand content with other consumers (e.g. colleagues, friends, family members) as well as, talking about their relationship with the brand products. As Kérastase content plan is mainly focused in posts offering brandrelated information, this seems to be in line with the findings of Tsai \& Men (2014) and Cvijikj \& Michahelles (2013) on engagement level. Moreover, it would be interesting to understand the distinct reasons among countries concerning the engagement to Kérastase Facebook. We may suggest that according to Tsai \& Men (2014) some cultures seem to look for brand SMP mainly for social purposes, while other cultures also seeks economic benefits, such as coupons, awards, and free samples. Finally, some consumers also use SMP to stress out some aspects they find to be less positive towards the brand, and very specific of each country business operation. In the case of USA and UK, the Kérastase consumers mentioned the service as something that was not satisfying. This can be explained as these two countries recently implemented direct online sales in a company whose customer care structure is not adapted to e-commerce, thus resulting in complaints. In IND the negative responses were related with units and company thus suggesting product unavailability and the lack of point of sales.

Keywords: cross-cultural effect, consumer-brand relationship, brand engagement, Kérastase, L'Oreal

Acknowledge: This work was supported by Fundação para a Ciência e a Tecnologia, grant UID/GES/00315/2019

\section{References}

Berry, L.L. (1983). Relationship marketing, in Berry, L.L., Shostack, G.L. and Upah, G.D. (Eds), Emerging Perspectives of Services Marketing (25-28). Chicago, IL: American Marketing Association.

Boyd, D.M., \& Ellison, N.B., (2008). Social network sites: definition, history, and scholarship. J Comput Mediat Commun, 13(1), 210-230.

Bowden, J. (2009). The process of customer engagement: A conceptual framework. Journal of Marketing Theory and Practice, 17(1), 63-74.

Brodie, R.J., Hollebeek, L.D., Juric, B. and Ilic, A. (2011). Customer engagement: Conceptual domain, fundamental propositions, and implications for research. Journal of Service Research, 14(3), 252-271.

Brodie, R.J., Ilic, A., Juric, B. and Hollebeek, L.D. (2013). Consumer engagement in a virtual brand community: An exploratory analysis. Journal of Business Research, 66(1), 105-114.

Cvijikj, I. P., \& Michahelles, F. (2013). Online engagement factors on Facebook brand pages. Social Network Analysis and Mining, 3(4), 843-861. 
Donthu, N., Yoo, B., (1998). Cultural influences on service quality expectations. Journal of Service Research, 1(2), 178-186.

Fan, W., Wallace, L., Rich, S., \& Zhang, Z. (2006). Tapping the Power of Text Mining. Communications of the AC, 49(9), 77-82.

Grier, S.A., Brumbaugh, A.M., (1999). Noticing cultural differences: ad meanings created by target and non-target markets. Journal of Advertising, 28(1), 79-93.

Grönroos, C. (1994). From marketing mix to relationship marketing: towards a paradigm shift in marketing. Management Decision, 32(2), 4-20.

Gummesson, E. (1996). Relationship marketing and imaginary organizations: A synthesis. European Journal of Marketing, 30(2): 31-44.

Hofstede, G. (1978). The Poverty of Management Control Philosophy. The Academy of Management Review, 3(3), 450-461.

Hollebeek, L.D. (2011a). Demystifying customer engagement: Exploring the loyalty nexus. Journal of Marketing Management, 27,(1), 785-807.

Hollebeek, L.D. (2011b). Exploring customer brand engagement: Definition and themes. Journal of Strategic Marketing, 19(7), 555-573.

Hunt, S.D. and Morgan, R.M. (1994). Relationship marketing in the era of network competition. Marketing Management, 3(1), 19-28.

Kozinets, R. V. (2002). The Field Behind the Screen: Using Netnography for Marketing Research in Online Communities. Journal of Marketing Research, 39(1), 61-72.

Kueh, K., Voon, B.H., (2007). Culture and service quality expectations: evidence from generation Y consumers in Malaysia. Managing Service Quality, 17(6), 656-680.

Men, L. R., \& Tsai, W. H. S. (2014). Perceptual, attitudinal, and behavioral outcomes of organization-public engagement on corporate social networking sites. Journal of Public Relations Research, 26(5), 417-435.

Mulki, J.P. \& Stock, J. (2003). Evolution of relationship marketing. Proceedings of Conference on Historical Analysis and Research in Marketing (CHARM), 52-59.

Parvatiyar, A., \& Sheth, J. N. (2000). The domain and conceptual foundations of relationship marketing, In A. Parvatiyar \& J. N. Sheth (Eds.), Handbook of relationship marketing (3-38). Thousand Oaks, CA: Sage Publications.

Sheth, J. N. and Parvatiyar, A. (1995). Relationship marketing in consumer markets: antecedents and consequences. Journal of the Academy of Marketing Science, 23(4), 255-271.

Simester, D.I., Hauser, J.R., Wernerfelt, B., Rust, R.T., (2000). Implementing quality improvement programs designed to enhance customer satisfaction: quasiexperiments in the United States and Spain. Journal of Marketing Research, 37(1), 102-112.

Sklar, C. (2013). How to Use Social Media to Understand and Engage Your Customers. The Guardian. http://www.theguardian.com/media-network/medianetworkblog/2013/mar/13/social-media-customer-engagement . Accessed on April 12, 2018.

Sprott, D., Czellar, S. and Spangenberg, E. (2009). The importance of a general measure of brand engagement on market behaviour: development and validation of a scale. Journal of Marketing Research, 46(2), 92-104.

Tsai, W. \& Men, L. (2014). Consumer engagement with brands on social network sites: A cross-cultural comparison of China and the USA. Journal of Marketing Communications, 23(1), 2-21.

Van Doorn, J., Lemon, K., Mittal, V., Naas, S., Pick, D., Pirner, P. and Verhoef, P. (2010). Consumer engagement behaviour: theoretical foundations and research directions. Journal of Service Research, 13(3), 253-266.

Vivek, S.D., Beatty, S.E. and Morgan, R.M. (2012). Customer engagement: Exploring customer relationships beyond purchase. Journal of Marketing Theory and Practice, 20(2), 122-146. 
2019 Global Fashion Management Conference at Paris

Table 1. Sample of analyzed comments and interactions

\begin{tabular}{llll}
\hline $\begin{array}{l}\text { Kérastase } \\
\text { Facebook }\end{array}$ & Facebook Fans & $\begin{array}{l}\text { Comments } \\
\text { Analyzed }\end{array}$ & Period \\
\hline USA & 132.107 & 678 & Jan 2016 to Aug 2018 \\
UK & 69.221 & 239 & Jan 2016 to Aug 2018 \\
IND & 167.868 & 548 & Jan 2016 to Aug 2018 \\
SA & n/a & 82 & Jan 2016 to Aug 2018 \\
\hline Total & & 1,547 & \\
\hline
\end{tabular}

